\title{
VESTIRES INDÍGENAS EM BONECAS KARAJÁ: ARGUMENTOS PARA UMA HISTÓRIA DA INDUMENTÁRIA NO BRASIL
}

\author{
Indigenous dress in Karajá dolls: reasoning for a \\ dress history in Brazil
}

Rita Morais de Andrade*

\begin{abstract}
RESUMO
Este artigo inaugura uma reflexão sobre o modelo de pensamento que origina a categoria "indumentária indígena" na história da indumentária no Brasil e sobre o modo como a formação dessa tipologia de coleções nos museus pode interferir na construção de valores éticos e estéticos dos modos de vestir. Apresentam-se aqui alguns desafios para uma história da indumentária a partir de estudos de coleções classificadas de étnicas, como as de indumentária indígena. Essa proposta baseia-se em análise da indumentária indígena nas bonecas karajá, as ritxoko, registradas como patrimônio imaterial brasileiro pelo Instituto do Patrimônio Histórico e Artístico - IPHAN, em 2012. A partir desse estudo seminal, discuto certos percursos metodológicos de pesquisa visando a construção de uma história da indumentária brasileira que considere a cultura material e as visualidades aspectos importantes de investigação. Concluo que essa indumentária indígena está apenas parcialmente indicada nos museus em suas coleções etnográficas, motivo pelo qual sugiro que o historiador considere conflitos sociais atuais quando incluir esse patrimônio cultural no corpus de sua pesquisa.
\end{abstract}

* Professora Associada da Universidade Federal de Goiás no Programa de PósGraduação em Arte e Cultura Visual e no Bacharelado em Design de Moda. Doutora em História Cultural pela PUC-SP. Líder do Grupo de Pesquisa do CNPq: INDUMENTA - dress and textiles studies in Brazil. 
Palavras chave: história da indumentária indígena e brasileira; bonecas karajá (ritxoko) e coleções de museus; patrimônio histórico nacional

\begin{abstract}
This paper inaugurates a discussion on the mental model which originates the category "indigenous dress" within the history of Brazilian dress and the ways in which the formation of museum collections may interfere in building ethical and aesthetic values of Brazilian peoples. I present some challenges for a history of dress based on collections classified as ethnic, such as indigenous ones through the study of Indigenous clothing in the Karajá dolls, the ritxoko, registered as Brazilian immaterial heritage by the Institute of Historical and Artistic Heritage - IPHAN, in 2012. From this seminal study, I discuss certain methodological research paths aimed at developing a history of Brazilian dress that considers material culture and visualities as resourcefull research tools. Conclusion is that this indigenous clothing is partially indicated in museums through the formation of its ethnographic collections, leading me to suggest that current social problems are considered critical points for a historical narrative on the subject.
\end{abstract}

Keywords: Indigenous and Brazilian dress history; Karajá dolls (ritxoko) and museum collections; national heritage.

"Não há poder maior no mundo, que o do tempo: tudo sujeita, tudo muda, tudo acaba"

Padre Antônio Vieira

\title{
Introdução
}

Proponho neste trabalho uma reflexão sobre os estudos de indumentária brasileira com base em acervos de objetos nos museus. O colecionamento de trajes e outros artefatos de vestir é um processo influente na construção de valores éticos e estéticos sobre modos de vestir. Selecionei a indumentária indígena, presente em bonecas 
karajá, as ritxoko, para apresentar questões-chave ao desenvolvimento de um campo de pesquisa centrada na concepção de "indumentária brasileira" como uma categoria histórica. Essas bonecas, feitas principalmente de cerâmica e adornadas com indumentária karajá, são patrimônio imaterial brasileiro registrado simultaneamente em dois livros de tombamento pelo Instituto de Patrimônio Histórico e Artístico Nacional - IPHAN em 2012 $2^{1}$.

A partir de um estudo preliminar sobre a indumentária nas bonecas, discuto alguns procedimentos teórico-metodológicos relativos às investigações baseadas em objetos, especialmente quando a finalidade maior é a de fornecer uma perspectiva histórica à indumentária brasileira a partir da cultura material patrimonializada. Recorri particularmente a uma abordagem antropológica perspectivista, a estudos sobre cultura material, e a orientações da área de museologia e antropologia para lidar com patrimônio cultural, com destaque para trabalhos de Eduardo Viveiros de Castro (2002), José Reginaldo Gonçalves (2007), Bruno Latour (2007), Manuela Carneiro da Cunha (2009) e Daniel Miller (2005 e 2013)².

Os trajes e pinturas corporais das ritxoko, selecionadas para este estudo, são visualmente similares àqueles vestidos por homens e mulheres karajá. Entretanto, percebo soluções criativas de representação da indumentária nas bonecas sem par na vestimenta indígena. Aparentemente, as escolhas dos materiais para a produção das bonecas foram historicamente afetadas pelas ocorrências de interlocuções culturais, transformando tanto a forma e visual das bonecas quanto o seu uso.

1 Dados do dossiê produzido entre 2008 e 2012 que subsidiou esse registro pelo Instituto do Patrimônio Histórico e Artístico Nacional (IPHAN). LIMA, Nei Clara de et al. Bonecas Karajá: arte, memória e identidade indígena no Araguaia. Dossiê Descritivo do modo de fazer ritxoko. Goiânia: Museu Antropológico, Universidade Federal de Goiás, IPHAN. 2011.

2 CUNHA, Manuela Carneiro da. Cultura com Aspas e outros ensaios. São Paulo: Cosac Naify, 2009. CASTRO, Eduardo Viveiros de. A inconstância da alma selvagem e outros ensaios de antropologia. São Paulo: CosacNaify, 2002. GONÇALVES, José Reginaldo Santos. Antropologia dos objetos: coleções, museus e patrimônios. Rio de Janeiro: IBRAM, 2007. LATOUR, Bruno. Reassembling the Social: an introduction to actor-network-theory. Oxford University Press, 2007. MILLER, Daniel. Trecos, Troços e Coisas: estudos antropológicos sobre a cultura material. Trad. Renato Aguiar. Rio de Janeiro: Zahar, 2013 (2010). MILLER, Daniel. Introduction. In: MILLER, Daniel and KUCHLER, Susanne. Clothing as Material Culture. Berg, 2005, p.1-19. 
Concluo que para realizar alguma história da indumentária brasileira nesses termos, parece adequado manter uma abordagem antropológica perspectivista. Igualmente adequado seria rever as questões relevantes a este campo de pesquisa para atualizá-las e aproximá-las dos interesses sociais atuais em relação aos problemas historicamente construídos. Defendo, finalmente, situar esses estudos em relação à especialidade da indumentária como objeto e tema de pesquisa e, por fim, mas muito importante, valorizar os objetos a as visualidades como recursos de análise para a História. Este artigo busca, desta forma, responder a uma questão ampla sobre a possibilidade de se escrever uma história da indumentária brasileira, neste caso a de tradição indígena, a partir do estudo de acervos de museus sem limitar-se a eles.

\section{Indumentária indígena no contexto dos estudos sobre indumentária, os dress studies}

Estudos especializados em indumentária indígena são raros quando comparados aos estudos de outros tipos de indumentária, a exemplo daquelas de tradição ocidental como a moda. Sobre moda e indumentária de tradição ocidental há um considerável número de publicações. Das obras de referência aos periódicos especializados, podemos contar atualmente com uma variedade de publicações inédita na historiografia deste campo. Destaques dessa produção são as obras que defendem a criação e consolidação de uma área específica de pesquisa temática sob denominações aproximadas, tais como "Dress Studies", "Dress History”, "Fashion Studies"”.

3 Quatro obras de referência podem ser destacadas: TAYLOR, Lou. Establishing Dress History. Manchester University Press, 2004; TAYLOR, Lou. The Study of Dress History. Manchester University Press: 2002; CUMMING, Valerie. Understanding Fashion History. Costume and Fashion Press, 2004; BLACK, S., DE LA HAYE, A., ENTWISTLE, J., Rocamora, A., ROOT, R.A. and THOMAS, H., eds. The handbook of fashion studies. London: Berg, 2013. 
Há um número crescente de publicações e dossiês dedicados à novas questões, a exemplo deste presente dossiê, sugerindo uma amplificação e diversificação das ideias resultantes, sobretudo, de atividades acadêmicas e de museus. Essa nova condição da literatura especializada, que já sofreu pela escassez e raridade, é inédita. Trabalhos recentes demonstram uma mudança na percepção das questões-chave de pesquisa da área. Das temáticas mais populares destacam-se aquelas que buscam investigar a moda fora do contexto da tradição ocidental e outras que discutem modelos teóricometodológicos recorrentes nas pesquisas da área. Muitos desses trabalhos estabelecem uma relação entre os dois modelos: a tradição ocidental da moda e outras tradições, muitas vezes a partir da ideia central que a moda ocidental influenciou outras modas. Alguns deles começam a apresentar uma análise comparativa mais equilibrada em que percebemos uma influência recíproca entre os modelos comparados. Dentre esses, merece destaque o estudo sobre leques com plumária indígena da coleção do Instituto de Artes da UFRJ ${ }^{4}$.

Curiosamente, entretanto, não há indício, a partir do número de publicações recentes, de um interesse expressivo do campo pela temática "indumentária indígena brasileira". Nos periódicos especializados publicados na última década, essa temática está quase ausente. Das raras exceções, além de trabalho já mencionado sobre leques com plumária (2016), posso mencionar um capítulo de livro sobre cultura, corpo e moda brasileira publicado na enciclopédia mundial da moda (Berg, 2012) e uma comunicação de congresso científico na área de História (2016) ao qual ainda não tive acesso ${ }^{5}$. Já a indumentária indígena de outros países americanos vem sendo estudada com um pouco mais de interesse especializado. A mexicana, por exemplo, é uma das mais citadas em periódicos revisados por

4 VOLPI, Maria Cristina. "The Exotic West: The Circuit of Carioca Featherwork in the Nineteenth Century". In: Fashion Theory: the jornal of dress, body and culture. Special Issue: Brazilian Fashion. New York: Taylor \& Francis, Volume 20, Issue 2, 2016, pp.127-152.

5 VOLPI, op.cit.; ANDRADE, Rita Morais de e ROOT, Regina A. "Brazilian Dress Body and Culture". In: EICHER, Joanne B., SCHEVILL, Margot Blum (eds.). Berg Encyclopedia of World Dress and Fashion Volume 2, 2011, p. 421-425.; BICALHO, Poliene Soares dos Santos. A arte de "vestir-se": a indumentária indígena como cultura material e imaterial. In: Anais do Seminário de Pesquisa, Pós-Graduação, Ensino e Extensão do Câmpus Anápolis de CSEH (ISSN 2447-9357). Apenas resumo disponível em: http://www.anais.ueg.br/index.php/sepe/article/view/7016. Acesso em: abril de 2017. 
pares nos últimos dez anos e uma das poucas a ter uma publicação temática em forma de livro ${ }^{6}$.

Dos periódicos nacionais especializados em estudos sobre moda, o maior interesse temático está ainda na moda de tradição ocidental e quando o assunto é moda brasileira, os temas estão mais associados a períodos históricos específicos, a biografia de estilistas e a uma variedade temática da moda e design contemporâneos. Há alguma variedade nas perspectivas teórico-metodológicas nesses trabalhos. Muitos estão baseados na literatura e análise de imagens a partir de abordagens da semiótica, notadamente empregadas nos temas da publicidade e do marketing de moda. Em menor quantidade, mas ganhando interesse crescente dos pesquisadores brasileiros e estrangeiros, estão os que se baseiam em documentos de arquivos e museus a partir de abordagens da história e da cultura material ${ }^{7}$. Dos mais de trezentos artigos publicados nas principais revistas especializadas nos últimos dez anos, não há sequer um com a temática indumentária indígena brasileira ${ }^{8}$. O desinteresse pela temática é notável e revela uma deficiência da área de pesquisa em discutir tradições indumentárias nacionais.

São os trabalhos das áreas de antropologia e história que mais apresentaram a indumentária indígena sem elevá-la, no entanto, à condição de tema central da pesquisa. Nessas áreas há contribuições importantes para o conhecimento desse tema, com destaque para os trabalhos etnográficos de Berta Ribeiro (1988 e 1989a) e análises históricas e antropológicas de Manuela Carneiro da Cunha (2009) ${ }^{9}$. Apesar disto, esses trabalhos não dão conta de questões próprias da

6 As plataformas consultadas, (últuma atualização feita em abril de 2017) para a busca de artigos arbitrados por pares foram: o Portal de Periódicos Capes e Scopus. Apenas na primeira localizei 95 artigos, dos quais 40 citavam indumentária indígena mexicana. O livro citado é: STRESSER-PEAN, Claude. Des vetements et des homes: une perspective historique du vetement indigene au Mexique. Paris: Riveneuve Éditions, 2011.

7 Alguns publicados no número especial sobre moda brasileira da revista Fashion Theory: the journal of dress, body and culture, vol. 20, n.2, 2016).

8 Consultei os seguintes periódicos nacionais arbitrados pelos pares e disponíveis em versão digital: ModaPalavra, revista publicada semestralmente desde 2008 (da versão impressa há números anteriores não consultados); revista DoBras, publicada semestralmente desde 2007; revista Iara. Busquei sistematicamente pela temática indígena brasileira tendo como critério o título de todos os trabalhos publicados em todos os números dos três periódicos.

9 CUNHA, 2009, op.cit. RIBEIRO, Berta Gleizer. Dicionário do artesanato indígena. Itatiaia Edusp, 1988; e RIBEIRO, Berta Gleizer. Arte indígena, linguagem visual. Itatiaia Edusp, 1989. 
área de estudos sobre indumentária, como as tecnologias têxtil e de vestuário, a coloração, o estilo e as implicações da produção e da circulação desses objetos na vida social. A própria área especializada vem adiando o debate sobre os interesses atuais que estão em jogo na construção de uma história da indumentária brasileira.

\section{Indumentária indígena no contexto da história da indumentária brasileira e do patrimônio nacional}

Pensar em uma indumentária relativa a um país, a uma nação ou a um povo, implica dar contornos às formas de vestir que traduzam ou identifiquem essa nacionalidade ou cultura correspondente. Se há uma indumentária brasileira que não seja, por oposição ou contraste, uma indumentária japonesa ou uma indumentária chilena, com quais critérios examinamos suas especificidades enquanto a comparamos às outras? Para não naturalizar uma noção de indumentária brasileira, vamos admitir que lidar com um conceito de nacionalidade implica fazer reduções nem sempre adequadas do ponto de vista micropolítico. Assim, apesar do esforço para não reduzir tradições indumentárias indígenas à "roupa de índio", não é ainda possível escrever uma história dessas tradições de forma a contemplar suficientemente suas variáveis, já que este é um campo de investigação bastante incipiente. De qualquer modo, é preciso começar a discutir esse tema.

Indumentária, no modo que a empregamos inicialmente neste trabalho, é o conjunto de artefatos que vestem o corpo. O conceito não está limitado ao vestuário (trajes e complementos de trajes), mas é aplicável também aos adornos corporais, inclusive pinturas. Esse conceito amplo é particularmente vantajoso para compreender em diversidade os modos de vestir e, talvez, mais adequado para considerar indumentária por uma perspectiva antropológica, como cultura material que não deve ser compreendida dissociada da vida 
social, sob o risco de reificar equívocos históricos que serão discutidos à frente ${ }^{10}$.

Em relação às noções de nacionalidade, brasilidade e cultura brasileira, essas já foram e continuam a ser discutidas por cientistas sociais e não serão retomadas aqui. $O$ interesse pelas "imagens do Brasil", nas palavras de Renato Ortiz (2013), permanece como um sintoma da nossa experiência colonial ${ }^{11}$. Esta visão de imagens sobre a cultura e a história brasileira, da qual compartilho, serve como um índice e pode ser útil para dar conta de algumas questões comuns aos brasileiros, sem esgotar suas variantes micropolíticas ${ }^{12}$.

A ideia de uma "indumentária brasileira" neste artigo, portanto, vincula-se a esta ampla noção de história e cultura brasileira, visando identificar a diversidade estética e ética que compõem esse tema, sem perder de vista os contornos históricos que a constituíram. Os critérios para relacionar essa composição são prioritariamente elencados a partir da diversidade populacional do Brasil em sua história, mas há muito que avançar nesses critérios. Faz sentido, a partir dessa premissa, estudar a "indumentária indígena brasileira", que pode inicialmente ser compreendida como o conjunto de artefatos e imagens concretos e imaginários que vestem o corpo, entre estes estão trajes e seus complementos, pinturas corporais e máscaras de diversos tipos e materiais, que sejam de tradições culturais indígenas.

10 Discuto o estudo da indumentária como uma categoria antropológica em artigo publicado na revista MUSAS/IBRAM (2016) ANDRADE, Rita Morais de. "Indumentária nos museus brasileiros: a invisibilidade das coleções". In: Musas: Revista brasileira de museus $e$ museologia, n.7, 2016, p.10-31.

Sobre o tema da cultura material e sua relação com a vida social nos termos empregados neste artigo, consultei: MILLER, Daniel (ed.). "Introduction". In: Why somethings matter. University College London Press, 1998, p.3-24; MILLER, Daniel. Artefacts and the meaning of things. Museums in the Material World, p. 166-186, 2007; LATOUR, Bruno. "Third Source of Uncertainty: Objects too Have Agency". In: Reassembling the Social: an introduction to ActorNetwork-Theory. Oxford University Press, 2005, p.63-86. Disponível em: http://www.dssedit.com/plu/Latour_Reassembling.pdf .

11 ORTIZ, Renato. "Imagens do Brasil". In: Revista Sociedade e Estado, Volume 28, Número 3, Setembro/Dezembro 2013, p.609-633.

12 As histórias do Brasil ganharam interesse renovado nos últimos anos. Alguns dos novos trabalhos incluem a cultura visual e a material como importantes documentos nesse campo de investigação. Nesta perspectiva, destaco: SCHWARCZ, Lilia Moritz Schwarcz, STARLING, Heloisa Murgel. Brasil: uma biografia. Companhia das Letras, 2015. 
Um dos caminhos para o estudo de indumentária é aquele que a insere no contexto do patrimônio material e imaterial da humanidade. A intangibilidade das ações corporais, incluindo-se aí a oralidade e o imaginário, são marcos importantes para estudos sobre indumentária brasileira, tanto quanto a materialidade. Neste trabalho o foco está nos objetos musealizados que constituem por norma ou intenção o patrimônio cultural material e imaterial do país. Há uma quantidade considerável de artefatos indígenas brasileiros, incluindo indumentária, nos museus que são, aparentemente, pouco estudados, mas que estão ganhando crescente interesse da museologia brasileira $^{13}$.

A orientação do Comitê de Indumentária do Conselho Internacional de Museus - COSTUME/ICOM, no que se refere ao registro de indumentária em museus, é apoiar-se na simplificação do uso de termos especializados como um método eficaz de trabalho que atende à grande maioria dos museus associados. Conforme explicou Anne Buck na introdução do guia de terminologia para acervos de indumentária ${ }^{14}$ :

Na elaboração de terminologia dos itens de vestuário, trabalhamos sempre a partir dos próprios objetos e em sua relação com o corpo e não com nenhuma teoria da classificação que introduzia outros fatores. Os termos e seu agrupamento não levam em conta a função especial, mas a terminologia deve ser vista dentro do contexto da lista de informações básicas onde a função aparece como uma entrada separada, seguindo o nome do objeto. Então,

13 Dentre as publicações recentes sobre as coleções indígenas nos museus brasileiros, consultei: CURY, Marília Xavier (org.). Museus e indígenas: saberes e ética, novos paradigmas em debate. São Paulo: Secretaria da Cultura; ACAM Portinari; Museu de Arqueologia e Etnologia-USP, 1a ed., 2016. Disponível em: http://www.livrosabertos.sibi.usp.br/portaldelivrosUSP/catalog/download/86/74/3591?inline $=1$. Acesso em: 20/02/2017.

14 In: Introduction. Vocabulary of Basic Terms for Cataloguing Costume. ICOM International Committee for the Museums and Collections of Costume. Disponível em: http://old.collectionstrust.org.uk/assets/thesaurus_icombts/vbt_ie.htm. Acesso em: 02/04/2017. 
o termo básico para vestido de banho [traje de banho] ou vestido de noiva é Vestido ${ }^{15}$.

Esse método, pouco difundido nos museus brasileiros com acervos de indumentária, mostra-se um ponto de partida facilitador na pesquisa, quando é necessário proceder com a descrição dos objetos. Porém, conforme avançamos na identificação de indumentária indígena, não encontramos um suporte adequado nessa base internacional de terminologia. Talvez aqui esteja uma contribuição ainda aberta que poderá ser dada à área a partir do estudo de coleções indígenas nos museus brasileiros.

Entender a indumentária como cultura material e a partir de uma perspectiva antropológica e como categoria histórica, pode contribuir com a discussão a respeito da patrominialização e musealização dos modos de vestir. Indumentária pode ser vista como algo que conecta pessoas em diferentes estratos (pessoal, coletiva, local, global) e dimensões (histórica, política, econômica) da vida social. A materialidade das roupas torna visível alguns desses indicadores da dinâmica social, daí a contribuição que estudos baseados em objetos podem trazer à história como à antropologia.

A respeito da musealização e da patrimonialização de indumentária, há problemas específicos inicialmente discutidos em outros trabalhos ${ }^{16}$. Aqui importa retomar a ideia de que as coleções nos museus não representam a diversidade cultural brasileira. Distante disto, há determinados grupos mais (e não melhor) representados nos museus, como os militares e os índios. Há ainda outras preferências temáticas para a indumentária nos museus, como a moda, especialmente, mas não exclusivamente, a feminina. Essas preferências estão alinhadas à visão antiga e anacrônica da história do Brasil no que diz respeito às divisões sociais entre os brasileiros, a

15 Tradução livre da autora do original: "In the naming of garments we worked always from the objects themselves and their relation to the body and not to any theory of classification which introduced other factors. The terms themselves and their grouping do not take account of special function, but the naming has to be seen within the context of the list of basic information where function appears as a separate entry, following the name of the object. So the basic term for bathing or wedding dress alike is Dress."

16 ANDRADE, 2016, op.cit. e ANDRADE e ROOT, op.cit. 
saber: os índios, os brancos (militares e civis) e os negros (escravizados e libertos).

A composição das atuais coleções de indumentária em museus brasileiros ajuda a dar contorno à concepção de "indumentária brasileira indígena". Como discutiremos adiante, a formação das coleções reflete estruturas e preferências políticas relativas à visão social historicamente constituída. De modo que, será preciso atuar com cautela na prescrição de modos de vestir a cada grupo brasileiro. Em outras palavras, assim como faz Eduardo Viveiros de Castro (2002) quando usa o conceito de perspectivismo para estudar grupos indígenas ${ }^{17}$, creio ser importante evitar reificar modelos mentais em que as intenções e interesses da pesquisadora (e com ela os seus marcos culturais) subjuguem aqueles que estão na condição de objetos ou sujeitos da investigação.

Assim, para o estudo da indumentária interessa tanto, ou mais, conhecer as visões de mundo apenas indicadas nos objetos e que nos permita refletir sobre as nossas próprias concepções naturalizadas. Para isto, não seria adequado realizar análises comparativas com vistas a categorizar, por exemplo, modos de vestir. Antes, seria necessário compreender se "modos de vestir" é conceito ou prática que possa ser traduzida ou encontrada naquele grupo. A literalidade dos objetos pode ser útil, talvez mesmo necessária, para dar chão à metodologia de pesquisa, mas não sem estar associada à sua opacidade ${ }^{18}$.

Partindo desse princípio, parece inadequado transferir às coleções indígenas dos museus brasileiros a capacidade de representatividade integral de modos de vestir indígenas, já que a própria concepção de "modos de vestir", ou "indumentária", podem não encontrar par nas diversas visões de mundo desses vários grupos. De modo que, encontramos aqui um paradoxo e um desafio à

17 CASTRO, 2002, op.cit. e SZTUTMAN, Renato (org.). Eduardo Viveiros de Castro (Coleção Encontros). Rio de Janeiro: Beco do Azougue, 2008.

18 Sobre a literalidade e a opacidade (ou o oculto), há discussões relacionadas à vários temas, como religião e literatura. Para as artes visuais, posso citar uma publicação recente que esclarece o termo empregado aqui. ALLOA, Emmanuel. Entre a transparência e a opacidade - o que a imagem dá a pensar. In: ALLOA, Emmanuel (org.). Pensar a imagem. Belo Horizonte: Autêntica, 2015 pp.7-22. 
metodologia de pesquisa para investigar a "indumentária indígena" e, consequentemente, a "indumentária brasileira".

A antropóloga Els Lagrou (2009) que estudou a temática "arte indígena no Brasil" apresenta uma análise a partir de sua pesquisa etnográfica que pode ser um modelo, ao menos inicial, para pensarmos num estudo de indumentária indígena que respeite $\mathrm{o}$ perspectivismo cultural ${ }^{19}$. Nos trechos em que trata da produção de tecidos e indumentária - como redes, panos de vestir, perneiras, tornozeleiras e saias -, por diferentes grupos étnicos indígenas brasileiros, a autora destaca que há diferenças sensíveis entre a tradição ocidental e a desses povos de situarem a produção material na vida social. Há vários exemplos em seu trabalho e, apesar de algumas especificidades de grupos como os amazônicos, os desenhos realizados nos tecidos e nas pinturas corporais não são comumente uma representação literal da aparência das coisas. Os desenhos, como os grafismos, são um tipo de porta que dá acesso à outros mundos chamados de sobrenaturais. Esses desenhos são indicações dos seres sobrenaturais ou de imagens invisíveis do mundo sobrenatural que sinalizam esses valores, mas que não os representam integralmente.

De forma que, não seria suficiente criar um léxico visual indígena a que pudéssemos recorrer e associar a determinados valores sem correr riscos de perder parte significativa nessa tentativa de tradução. Certamente isso não diminui a relevância dos trabalhos etnográficos que são referência para estudo de artefatos indígenas e inestimável contribuição para a área de pesquisa ${ }^{20}$. Contudo, há outras ações corporais envolvidas na produção de desenhos e objetos como trajes e adornos por esses grupos indígenas que não são redutíveis ao que é material e visível, como demonstrado em trabalho sobre o grafismo karajá ${ }^{21}$. Há cantos e canções, gestos e um imaginário que

19 LAGROU, Els. Arte Indígena no Brasil: agência, alteridade e relação. Belo Horizonte: C/Arte, 2009.

20 Trabalhos como os de: RIBEIRO, 1988, op.cit.; MOTTA, Dilza Fonseca da. Tesauro de cultura material dos índios no Brasil. Museu do Índio, FUNAI, 2006.

21 LIMA FILHO, Manuel Ferreira; SILVA, Telma Camargo da. A arte de saber fazer grafismo nas bonecas Karajá. In: Horizontes antropológicos, Porto Alegre, v. 18, n. 38, p. 45-74, Dec. 2012. Disponível em: <http://www.scielo.br/scielo.php?script=sci_arttext\&pid=S0104$71832012000200003 \& \operatorname{lng}=$ en $\&$ nrm=iso $>$. http://dx.doi.org/10.1590/S0104-71832012000200003. 
não acompanham ou não estão presentes visualmente nos artefatos, inclusive na indumentária. Seria, portanto, inadequado proceder uma análise descritiva dos trajes, por exemplo, e crer que do visível extraímos a estética verdadeira, uma "alma indígena". O que está visível é, senão, muitas vezes uma marca indicativa de algum valor que não está integralmente expresso nos desenhos, mas sutilmente indicados neles, conforme venho insistindo neste texto em relação à opacidade na literalidade.

A corporeidade é um aspecto da tradição cultural indígena brasileira que precisa ser considerado quando arte e artefato são estudados. Assim como Els Lagrou (2009) demonstrou que arte e artefato (ou arte e artesanato) são conceitos inseparáveis, ou talvez mesmo intraduzíveis à produção indígena, Oliveira (2015) entende essa divisão binária como algo superado, chamando a atenção para a necessidade de evitarmos falar da produção material indígena como um aspecto fundamentalmente funcional ${ }^{22}$. Assim, deveríamos evitar, para trazer a ideia ao nosso campo de investigação, reduzir a indumentária indígena feminina à descrição literal dos artefatos como tanga, colares de miçangas e brincos de plumas. Este tipo de descrição está mais alinhado com um modelo de pensamento que categoriza para generalizar, reduzindo os modos de vestir ao uso funcional e ao apelo visual que encerram em determinadas matrizes de imagem o que é ser "índia". Melhor opção parece estar na perspectiva antropológica de tradição, que nos levaria a adotar uma concepção de tradição indígena para a indumentária, relacionando objetificação e imaginação ${ }^{23}$.

O caminho alternativo, acompanhando este pensamento antropológico com o qual concordo, seria desenvolver uma sensibilidade para as sutilezas nem sempre visíveis na produção material. Parte dessa produção resulta em artefatos/arte visíveis e que podem ser classificados em algum tipo de linguagem, a partir de um

22 LAGROU, 2009, op.cit., e OLIVEIRA, Oseias de. Jeroky Mbaekua: aspectos da etnoarte indígena. In: Revista Brasileira de História \& Ciências Sociais, 01 Junho 2015, Vol.4(8), p. 358-368. Disponível em: https://www.rbhcs.com/rbhcs/article/viewFile/144/138. Acesso em $03 / 03 / 2017$.

23 Nessa concepção, tradição é um mecanismo mutante , mas não historicamente estável. Ver verbete "tradição" em SILVA, Kalina Vanderlei; SILVA, Maciel Henrique. Dicionário de conceitos históricos. São Paulo: Contexto, 3a ed., 2010, p.405-408. 
vocabulário controlado. Isto pode ser útil para um início de conversa, para identificarmos repetições, alterações, e em análises comparativas esses dados podem ser de grande auxílio. Para além disto, porém, se a história deve ir além da narrativa ou descrição dos fatos, gostaríamos de entender, ou buscar entender, o processo. Para estudar o processo no caso da indumentária indígena, teremos que relacioná-la a um modo próprio de conceber e vivenciar o mundo. Parece inescapável aceitar, portanto, que por mais que os museus busquem coletar e formar coleções bastante completas de indumentária indígena, esses artefatos não são a indumentária, se não uma visão ou dimensão relativamente parcial dela.

Estudar o tema "indumentária indígena" me parece, então, uma maneira profícua de refletir sobre a construção de uma história da indumentária brasileira, já que apresenta a oportunidade de discutir a alteridade em meio à grande diversidade cultural a que estamos habituados a relacionar ao Brasil.

\section{Estudar indumentária dos museus}

Quando se estuda indumentária de acervo de museus, considera-se o contexto de formação da coleção, as intenções institucionais e sua historicidade. Será preciso refletir sobre as razões pelas quais determinados objetos, e não outros, foram musealizados. Não será suficiente, ao menos para uma história da indumentária nos termos propostos neste trabalho, referir-se a um traje de museu como índice visual e material de um único e específico período histórico, mas sim compreendê-lo em sua ampla rede social ${ }^{24}$. Outro aspecto importante a ser notado é a seleção dos trajes pelos museus e também as ausências nas coleções, já que essa condição tem impacto sobre os Life of Things: Commodity in Cultural Perspective. Cambridge, Cambridge University Press, 1986. 
estudos dos acervos, como discutido em estudo sobre coleções têxteis no Brasil ${ }^{25}$.

Aparentemente, a formação das coleções indígenas nos museus acompanhou alguns critérios nem sempre esclarecidos. Um deles é o interesse da pesquisa antropológica que levou exemplares de uma diversidade de objetos indígenas para museus, inclusive os históricos ${ }^{26}$. Outros critérios incluem a doação de coleções particulares e a aquisição de artefatos em razão de interesses de pesquisa especializadas, normalmente vinculados às universidades públicas e privadas, como é o caso do Museu Antropológico da Universidade Federal de Goiás - MA/UFG, que possui um acervo com quase mil itens registrados como escultura cerâmica karajá, as bonecas ritxoko ${ }^{27}$.

No contexto dos museus, o colecionamento de artefatos indígenas insere-se na história da formação de coleções representativas da nacionalidade brasileira a partir do século XIX, assim como ocorreu em outros países que passaram pela experiência da colonização. A seleção dos artefatos para as coleções não obedece sempre aos mesmos critérios, sendo historicamente construída ${ }^{28}$. Se observarmos as coleções indígenas em museus brasileiros, algumas instituições receberam levas de doações e aquisições em períodos específicos que podem ser associados a importantes mudanças políticas com impacto sobre as populações indígenas. As décadas de 1940, 1970 e 1980 são particularmente presentes nos museus como

25 Há alguns trabalhos publicados sobre o tema, particulamente explorado por Teresa Cristina T. de Paula em relação à conservação têxtil no Brasil. Destaco sua tese: PAULA, T.C.T.de. Tecidos no Brasil: um hiato. (Tese de doutorado) Defendida na Escola de Comunicação e Artes/USP, 2006.

26 Caso da divisão dos acervos do Museu Paulista e a criação do Museu de Antropologia e Etnologia da USP. Ver MENESES, Ulpiano B.T. A problemática da identidade cultural nos museus: de objetivo (de ação) a objeto (de conhecimento). In: Anais do Museu Paulista, vol.1, no.1, São Paulo, 1993. Disponível em: http://dx.doi.org/10.1590/S0101-47141993000100014. Acesso em: 20/02/2017. e tese de PAULA, T.C.T. de op.cit, para um inventário de artefatos têxteis, incluindo indumentária, dessa coleção.

27 Dados do Projeto de Pesquisa "Presença Karajá: cultura material, tramas e trânsitos coloniais", que está em andamento e é coordenado por Manuelina Maria Duarte Cândido, professora de Museologia, FCS/UFG. Integram o projeto as pesquisadoras Nei Clara Lima e Rita Morais de Andrade, da Universidade Federal de Goiás e Ema Pires, da Universidade de Évora em Portugal, além de estudantes bolsistas das duas universidades.

28 GONÇALVES, op.cit.1996, 2007 
datas de entrada dos artefatos indígenas, como verificado no levantamento inicial do registro de entrada das bonecas karajá no MA/UFG ${ }^{29}$. Assim como observou Berta Ribeiro (1989b), os discursos ou as preferências de colecionamento passam a ser revistas nos museus a partir de uma nova visão sobre a experiência colonial ${ }^{30}$.

Nem todas as escolhas são da ordem dos interesses institucionais no que diz respeito às negociações na coleta e doação de artefatos indígenas nos e aos museus. As relações interpessoais, conforme pude inferir da literatura consultada e citada neste artigo, estão marcadamente presentes nas negociações para a formação das coleções. De visões de mundo a interesses ou preferências pessoais, os objetos indígenas (mas não só estes) estão nos museus também em razão das escolhas feitas pelas pessoas na rotina de suas tarefas profissionais nas instituições.

Aparentemente, persiste, ainda que de forma assintomática, uma predileção pelo colecionamento de objetos que destaquem as singularidades identitárias de grupos sociais. Talvez isto ocorra não intencionalmente, e certamente a beleza de muitos dos artefatos indígenas, estranhos à tradição ocidental, é um incentivo para a manutenção dessa escolha. Então, se colecionamos nos museus é muitas vezes para atender a uma necessidade ou vontade alheia à dos grupos cujos objetos são coletados. Esta característica da formação de coleções indígenas nos museus, o que inclui a indumentária, pode remeter, portanto, à uma prática ancestral de colecionismo do exótico.

\section{As ritxoko: um caminho para estudar indumentária indígena}

As bonecas ritxoko foram inicialmente produzidas para a brincadeira de crianças, principalmente meninas, mas incorporou

29 Conforme dados do Projeto em andamento "Presença Karajá...", op.cit.

30 RIBEIRO, Berta G. Museu e Memória. Reflexões sobre o colecionamento. In: Ciências em Museus 1 (2), 1989. 
outro uso, e passou a ser produzida também para o comércio turístico. Mas a importância da boneca para os karajá não se restringe à sua função de brinquedo ou de mercadoria. Uma visão bastante sugestiva sobre a produção das bonecas foi dada por Whan Chang (2010) para quem as ritxoko tornam visível a voz feminina karajá ${ }^{31}$. Essa ideia expressa muito bem a visão de outros pesquisadores para quem a produção de artefatos indígenas não pode estar separada da performance ou, para dizer de outra forma, da vida social mediada pelo corpo e pelo imaginário ${ }^{32}$.

Estudar indumentária karajá a partir das ritxoko tem algumas vantagens. Em primeiro lugar, a boneca localiza no corpo o uso dos itens de indumentária. Isto permite associar itens de indumentária das coleções às suas funções, o que poderia ser uma tarefa mais difícil sem a figura da boneca que servisse de parâmetro comparativo. $\mathrm{O}$ inverso também acontece e a partir das coleções de indumentária é possível identificar diferentes modos de representação da indumentária indígena nas bonecas. Um bom exemplo é a representação de braçadeiras, que nas bonecas mais parecem ser enfeites de cabelo, mas que são provavelmente a tentativa de reproduzir braçadeiras que vestem os punhos (Figuras $1 \mathrm{a}, 1 \mathrm{~b}$ e $1 \mathrm{c})^{33}$.

Uma outra vantagem no estudo das bonecas é perceber como o corpo modifica o sentido que atribuímos à indumentária. Há diferentes formas de corpo das bonecas como aquelas sem membros inferiores, sem braços e as que tem cabeças não humanas, representando seres sobrenaturais. A depender do ser representado, a indumentária é apresentada de uma determinada maneira, mas as características mais comuns à tradição karajá, como seus grafismos, são mantidas.

31 CHANG, Whan. Ritxoko: A voz visual das ceramistas Karajá . (Tese de Doutorado) Rio de Janeiro: UFRJ/EBA/PPGAV, 2010.

32 LIMA et.al. (2011), op.cit.; LIMA FILHO e SILVA, (2012), op.cit..

33 Esta observação foi feita durante visita exploratória ocorrida em abril de 2017 ao MA/UFG pelo grupo de pesquisadoras do Projeto "Presença Karajá, em que a Profa e antropóloga Nei Clara Lima e eu observávamos uma seleção de bonecas do acervo e discutíamos possibilidades de interpretação das vestimentas nas ritxoco. 

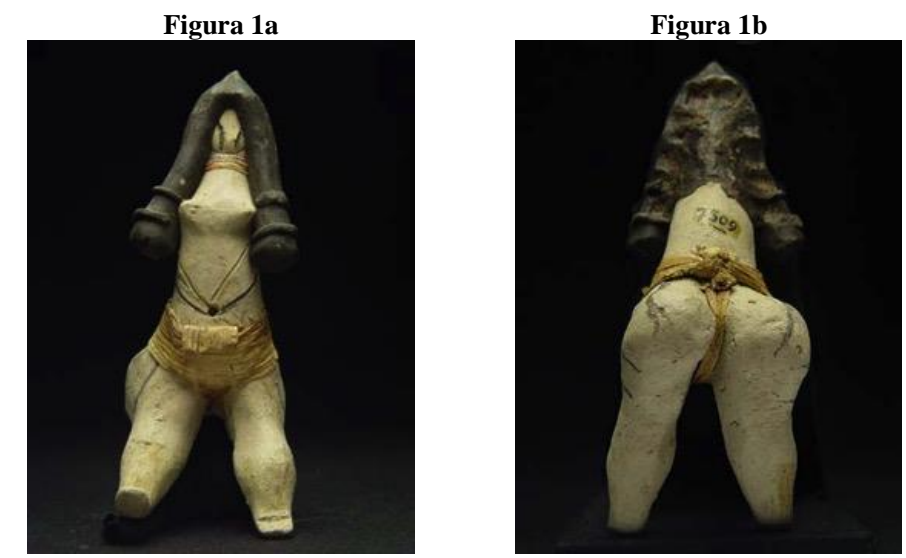

Figura 1c

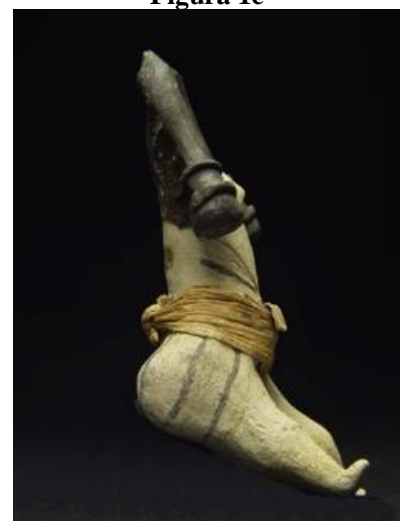

Figuras 1 a, b e c. Boneca karajá que representa o gênero feminino vestida com uma espécie de tanga feita em palha. Possui ainda incisões corporais, colares de fio têxtil e cabelo de cera, provavelmente de abelha. Vemos pinturas corporais na face e quadril. Há uma espécie de enfeite no cabelo que pode remeter às braçadeiras, usadas comumente por mulheres karajá nos punhos. É possível que esta seja uma forma criativa, e não literal, de representar itens de indumentária nas bonecas.

Imagem reproduzida do acesso digital ao acervo museológico do Museu do Índio, Rio de Janeiro. Número do registro: 7509. Boneca karajá de cerâmica. Tocantins. Coleção: Geraldo Pitaguary. Data de entrada no museu: 26/07/1958. Disponível em: http://base.museudoindio.gov.br/memoteca/semu/ceramica/a07/7509-f.jpg . Acesso em: 20/03/2017. 
Há ainda outras vantagens nesse tipo de recorte de pesquisa, como a visualização concreta das características corpóreas dos seres sobrenaturais visíveis apenas no imaginário, bem como de seus modos de vestir. Neste caso, as bonecas têm uma contribuição singular no estudo de indumentária já que servem de acesso ao imaginário karajá e suas tradições ancestrais. Isto pode ser visto, por exemplo, na ritxoko de múltiplas cabeças, nas tangas e pinturas corporais em preto e vermelho (Figura 2).

A boneca central, de muitas cabeças, mantém o padrão estético da indumentária karajá, como pode-se observar nas outras duas bonecas que a acompanham nesta imagem. Os grafismos e as cores são características marcantes na identificação da tradição karajá de vestir.

Figura 2

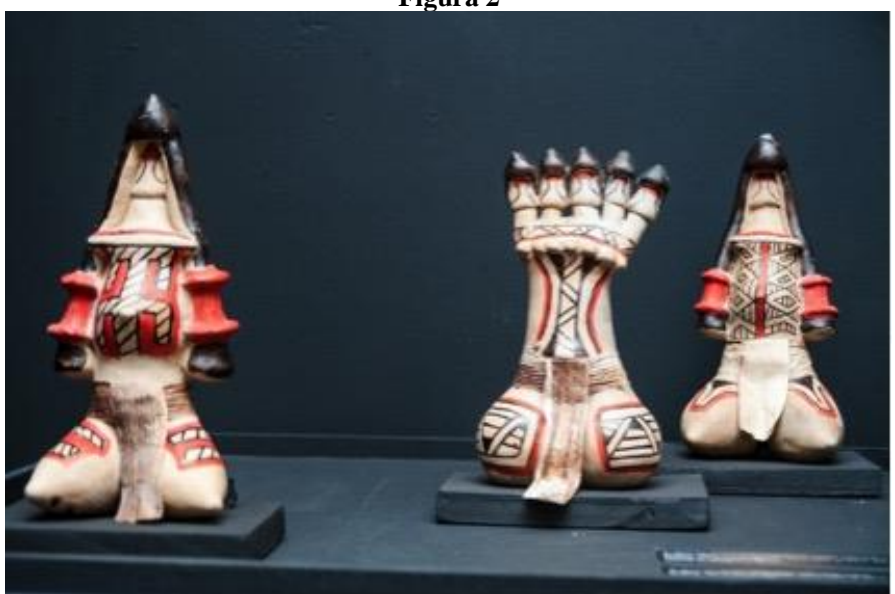

Fotografia de Markus Garscha realizada na remontagem da exposição Ritxoko: patrimônio do Brasil, durante a $63^{\mathrm{a}}$ Reunião da SBPC em Goiânia, na Escola de Música e Artes Cênicas da UFG, em julho de 2011. Originalmente, essa exposição foi realizada na Casa do Patrimônio, IPHAN Goiás, na cidade de Goiás, em junho de 2011, por ocasião do Festival Internacional de Cinema Ambiental - FICA. A curadoria é de Maíra Torres (IPHAN), Nei Clara Lima, Telma Camargo e Rosani Leitão (Museu Antropológico). Informações gentilmente fornecidas por Nei Clara Lima. 
As bonecas e sua indumentária não são apenas instrumentos de acesso à ancestralidade das tradições, são também meios para atualizar essas experiências passadas na vida social corrente. Quando crianças Iny, como os karajá se autodenominam, brincam de boneca, elas reproduzem alguns costumes dos quais não compartilham, se não pela experiência da reprodução de imagens da TV. Imagens realizadas para o vídeo documentário Ritxoko (2012) ${ }^{34}$, retratam meninas brincando com bonecas tradicionais vestidas com tecidos multicoloridos e atuais que cobrem todo o corpo, diferentemente das bonecas antigas e modernas que mantém as características de tradição indígena. As bonecas são posicionadas em salas divididas por rolos de tecidos simulando casas urbanas, distintas daquelas que as meninas habitam.

Quase todas as bonecas possuem algum tipo de ornamentação, entre as quais destacamos a pintura corporal (na escultura cerâmica), a vestimenta (tangas, colares, perneiras, tornozeleiras, etc.) e enfeites de cabeça (brincos de plumas, cabelos feitos em cera de abelha, etc). Os elementos mais comuns à todas as categorias de bonecas, inclusive as que representam o gênero masculino), são as pinturas corporais com uma diversidade de desenhos, mas de uso de cores restrito, destacando-se o preto e o vermelho como as cores que mais aparecem (Figuras 3 a,b,c). Com o tempo, o processo de oxidação pode tornar a cor vermelha em ocre. A cor é uma característica fundamental no estudo de indumentária, por isto queremos lembrar que artefatos antigos podem ter sofrido alteração das cores em função da idade.

34 Vídeo documentário Ritxoco, com duas versões, de 18 e 45 minutos e disponível em áudio na língua karajá e legendas em português e inglês. Apresentação do IPHAN, realização do Museu Antropológico da UFG, Produção Olho Filmes. Direção de Neto Borges. Roteiro de Manuel Ferreira Lima, Nei Clara De Lima, Neto Borges, Rosani Moreira Leitão, Telma Camargo da Silva. Fotografia de Neto Borges. Som: Raissa Ladeira e trilha sonora de Pedro Salles. Disponível em: http://www.olhoetnofilmes.com/ritxoco. 

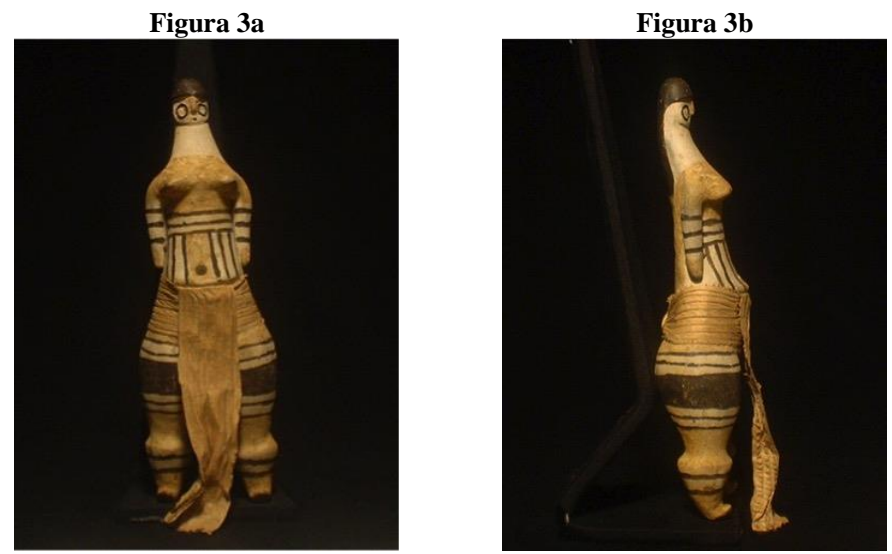

Figura 3c

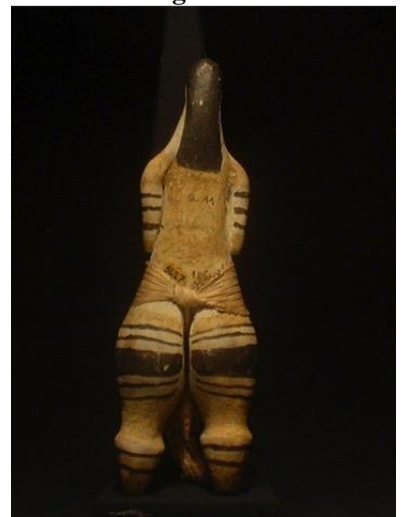

Figuras 3 a, b, c: respectivamente imagens de frente, lateral e verso de boneca karajá que representa o gênero feminino. Nas imagens vemos pinturas corporais e uma espécie de tanga feita aparentemente de palha com um modo característico de vestir as bonecas, assemelhado ao modo de vestir mulheres na tradição indígena karajá. Os círculos na face formam um desenho característico e não representam os olhos, como pode parecer em princípio.

Imagem reproduzida do acesso digital ao acervo museológico do Museu do Índio, Rio de Janeiro. Registro número 5627. Boneca Karajá. Tocantins. 1952. Dimensão e suporte: $18,5 \mathrm{~cm}$ de altura Disponível em: http://base.museudoindio.gov.br/memoteca/semu/ceramica/a05/5627-f.JPG Acesso em: 20/03/2017. 
Em relação aos materiais das vestimentas, também há alguma variação que pode ser identificada como sendo principalmente de fibras naturais (buriti e algodão são as mais comuns), mas as fibras artificiais (lã acrílica, por exemplo) também são encontradas. Há bonecas cobertas por vestidos de estilo mais semelhante à tradição ocidental, encontradas em coleções como as do Museu de Évora. É muito curioso observar as ritxoko vestidas ao modo ocidental, mas é também um possível caminho para datar as bonecas já que, dadas as mudanças estilística e tecnológica da moda, é possível identificar com certa precisão a data de fabricação dos tecidos. Este é um aspecto no estudo das bonecas que me interessa muito perseguir, especialmente porque associa a tradição ocidental à indígena de modos de vestir.

Adornos como tornozeleiras e perneiras são feitos da própria cerâmica ou de cera de abelha, o que varia principalmente de acordo com a idade da boneca. Itens semelhantes, em tamanho natural e feitos para vestir o corpo humano, são encontrados na coleção do MA/UFG e podem ser comparados às versões feitas para as bonecas. A diferença mais evidente está no uso de materiais, o que nos permite inferir, por exemplo, que a cera de abelha nas bonecas era um recurso de representação de itens de vestuário feitos originalmente, por exemplo, de material têxtil.

A diferença de materiais usados na produção de pulseiras e tornozeleiras das indígenas e das bonecas remete a uma semelhança na tradição ocidental de representação. Por analogia à representação de indumentária em bonecas ou em outros tipos de imagens como pinturas em telas, a vestimenta tende a ser representada de um modo simplificado. Isto significa dizer que a representação do que é vestido em outros meios parece ser produzido com o propósito de indiciar o que se veste, e não reproduzir a indumentária fielmente em outra forma (boneca, pintura). Mas será importante estudar ainda as diferenças e semelhanças entre bonecas antigas, anteriores a 1940 e modernas, produzidas a partir daquela década, uma espécie de marco histórico divisório amplamente aceito na literatura consultada. Uma das principais diferenças entre essas duas categorias está no material e modo de produção, sendo a moderna aquela feita em cerâmica.

Uma outra característica importante foi reportada pelas pesquisadoras que elaboraram o projeto e o dossiê para o registro das bonecas junto ao IPHAN. Além da reprodução sistemática de padrões 
de grafismos, que se repetem em vários objetos da exuberante cultura material dos Karajá, as ceramistas também gostam de inovar, misturando aos padrões pequenas intervenções autorais. A intervenção criativa das ceramistas sobre a produção das bonecas foi registrada por uma antropóloga participante daquele projeto, que escreveu $^{35}$ :

Para as ceramistas existe uma elaboração de figuras e um modo de fazer próprio à dinâmica interna do grupo que associa criatividade individual aos padrões do conhecimento tradicional. A tradição é reapropriada e reinventada a partir de um conhecimento coletivo. Por outro, uma ideia de tradição, configurada no objeto pertencente a coleções musealizadas, datadas no passado - veiculada por agentes não-índios.

É nessa inventividade que percebo mais uma associação possível entre as tradições de vestir, a ocidental e a indígena. A criatividade é valorizada na moda, por exemplo, porém através de diferenciação estilística marcante entre os produtores, ao passo que no processo de produção e vestimenta das bonecas, a criatividade aparenta ser algo mais sutil e melhor reconhecido por iniciados.

\section{Breve nota sobre os materiais e métodos da pesquisa}

Os dados para este trabalho foram coletados do dossiê de pesquisa sobre as bonecas karajá; das visitas ao MA/UFG e à reserva técnica com observação de uma seleção de bonecas; e de registros em

35 SILVA, Telma Camargo da. Modos de fazer Boneca Karajá, circulação de conhecimento e a construção do território. Trabalho apresentado no Núcleo de Estudo de Povos Indígenas - NEPI, UFSC, em 2013, e derivado da sua participação no projeto de pesquisa que resultou no já citado Dossiê Descritivo do modo de fazer ritxoco (LIMA, 2011). Disponível em: http://nepi.ufsc.br/files/2013/11/Paper-Telma-Camargo-da-Silva-NEPI1.pdf. Acesso em: 30/03/2017. 
imagens realizadas pelo grupo em visitas aos museus ${ }^{36}$. Para estudar essa coleção com os objetivos restritos a este artigo, tomamos exemplares das bonecas femininas e das bonecas dos seres sobrenaturais. Metodologicamente, agimos da seguinte forma para a análise: a.) seleção dos objetos; b.) descrição dos objetos e separação em categorias artificiais para fins de análise; c.) cotejamento das características observadas nos objetos com a literatura especializada em indumentária e cultura indígena; d.) identificação e descrição das lacunas e impressões para caminhos de pesquisa no desenvolvimento de uma história da indumentária indígena.

A seleção das bonecas para análise ocorreu basicamente por dois meios: visita ao MA/UFG e seleção de imagens produzidas e levantadas em arquivos e literatura secundária pelo grupo de pesquisadoras envolvido no projeto. Estamos, portanto, em fase inicial de discussão e os resultados apresentados devem ser considerados em progresso. A pesquisa está contextualizada em relação aos objetivos mais amplos do grupo: fazer levantamento de coleções de bonecas karajá em acervos de museus brasileiros e estrangeiros; investigar a produção e a circulação das bonecas em projeção histórica e em relação aos usos da boneca na vida social atual da sociedade karajá do rio Araguaia. O estudo da indumentária, portanto, integra-se a esses objetivos, buscando refletir sobre como o modo de estudar indumentária a partir de coleções de museus, incluindo o uso de artefatos como bonecas, pode contribuir para a produção de uma história da indumentária brasileira.

\section{Considerações finais}

O interesse político e social pelas populações indígenas brasileiras tem se destacado nos últimos anos. Há marcos na legislação brasileira, como na constituição de 1988, que procuram

36 LIMA et al., op.cit.. 
orientar soluções a problemas históricos relativos à cultura e terras indígenas no país. Os tradicionais mecanismos de coleta de dados populacionais buscam desenhar novas formas de inclusão da ancestralidade indígena ao censo. O Instituto Brasileiro de Geografia e Estatística - IBGE, incluiu a "raça indígena" no censo demográfico a partir de 1991, mas somente em 2010 foi criada a possibilidade de auto declaração da etnia e língua não apenas para os habitantes das terras demarcadas pelo governo como sendo indígenas, mas também fora delas ${ }^{37}$.

Além dos medidores populacionais e legislativos, o interesse crescente pelas questões indígenas é percebido pelo aumento de publicações acadêmicas e de ampla divulgação, como acontece notadamente em periódicos digitais a exemplo do jornal Nexo e da revista $\mathrm{FAPESP}^{38}$. O estudo da indumentária brasileira, nesse caso a indígena, relaciona-se estreitamente com esse contexto de interesses renovados pelas populações e culturas indígenas e pode ser um caminho para refletir sobre a sua presença nos museus.

Registros do patrimônio cultural indígena são igualmente recentes. As bonecas de cerâmica Karajá são apenas o $25^{\circ}$ bem registrado no país como patrimônio cultural imaterial brasileiro, o que foi realizado doze anos depois do primeiro registro junto ao IPHAN ${ }^{39}$. Além disso, a maior parte da literatura relativa a esse patrimônio, com algumas exceções como os trabalhos mais antigos de Berta Ribeiro e Manuela Carneiro da Cunha, foi publicada nos últimos vinte anos, com uma concentração maior nos últimos dez a cinco anos. Já as publicações sobre indumentária indígena em outros países da América Latina, como a do México, indicam um novíssimo olhar sobre o tema e uma oportunidade de desenvolvimento desse campo no Brasil.

37 Dados disponíveis em: http://indigenas.ibge.gov.br/estudos-especiais-3/o-brasilindigena . Acesso em: 28/03/2017.

38 Entre os textos de divulgação de pesquisa científica relacionadas ao tema indígena no Brasil, recomendo fortemente o acesso ao webdocumentário sobre a história da Amazônia publicada na revista FAPESP em março de 2017. Disponível em: http://revistapesquisa.fapesp.br/webdoc/amazonia/index.html . Acesso em: 25/04/2017. Já o Nexo está disponível em: https://www.nexojornal.com.br/

39 LIMA, 2011, op.cit. 
Para uma história da indumentária, acredito, importa investigar a função social dos trajes, discuti-los frente às questões importantes para a vida social atual; destacar particularidades que ajudem a ampliar o conhecimento do todo; reconhecer as deficiências e as forças do campo de pesquisa; considerar os contextos e situar a indumentária relativamente ao estudo da cultura, sem proceder, com isto, a um estudo anacrônico e reducionista. Inserir a indumentária no conjunto dos documentos da pesquisa é reconhecer que a vida social e a cultura podem ser estudadas também a partir dos modos de vestir. Para isto, entretanto, é preciso entender indumentária como um conceito amplificado, que inclui os artefatos e os processos.

\section{Agradecimentos}

A autora agradece: as organizadoras desse dossiê pelas sugestões que levaram à versão final do texto; o grupo de pesquisadoras que integram o projeto "Presença Karajá: cultura material, tramas e trânsitos coloniais" da Universidade Federal de Goiás, em especial as Profas. Manuelina Duarte Cândido e Nei Clara Lima pelos comentários sobre a versão inicial desse texto; o fotógrafo Markus Grasha que gentilmente autorizou a reprodução de uma fotografia sua (figura 2); a diretora e demais funcionários do Museu Antropológico da UFG.

RECEBIDO EM: 01/03/2017

APROVADO EM: 10/07/2017 